\title{
A Building Management Evaluation Method Based on BP Neural Networks
}

\author{
Zhenlin Yan*
}

Department of Engineering Economics, Henan College of Finance \& Taxation, Zhengzhou, Henan, 451464, China

\begin{abstract}
On the basis of in-depth study of the large number of documents, current theoretical research on overseas construction management evaluation methods is summarized. Many advanced building management theories and current models are described, as well as learnt government regulations. The study also discussed the basic building management assessment methods employed currently. On the basis of research results based on the major factors influencing construction management in the relevant literatures, a building evaluation system is built for the evaluation of a single object management architecture. The system includes: selecting the artificial neural networks comprehensive evaluation method, obtaining the sample data by questionnaire method, establishing a management evaluation model based on BP artificial neural network architecture, and applying and testing the model to evaluate the actual construction management.
\end{abstract}

Keywords: BP neural networks, construction management, evaluation methods, evaluation index system.

\section{INTRODUCTION}

Since the reform and opening up, China's cities have begun to develop rapidly. As of 2010, the total number of China's cities has been established as 216 cities in the beginning of reform, which have now increased to 657, an increase of more than twice. China's urban population increased from 172 million to 666 million people, so that China's urbanization rate has reached $49.68 \%[1,2]$. By 2015 , it is expected to reach $52 \%$, by 2030 will reach $65 \%$ and by 2050 will increase to about $75 \%$. In the rapid progress of urbanization process, the need for large-scale construction projects and related urban infrastructure construction requires large amounts of energy and resources.

However, the current urban development promoted by the development model of China's cities is almost unsustainable. In this environment, urban building management is particularly necessary. Urban architecture development model needs to transform itself. It is the fate of the human face of economic and social development which cannot be changed. To deal with environmental issues raised by carbon emission leading to ecologically low carbon resources buildings, is an inevitable choice.

Architecture not only takes all kinds of energy, integrated vector resource consumption, but also is an important carrier of urban development. According to the World Watch Institute, building global annual production consumes $16 \%$ water, $25 \%$ of the wood and about $40 \%$ of the gravel. Construction and operation of the construction process consumes about $45 \%$ of total annual global energy demand. In the global environmental pollution in general, constructionrelated environmental pollution accounts for nearly $34 \%$.

*Address correspondence to this author at the Department of Engineering Economics, Henan College of Finance \& Taxation, Zhengzhou, Henan, 451464, China; Tel: 13598063005; E-mail: yanzl1997@126.com
China's existing building area has more than 40 billion square meters, an annual area of approximately 18-20 million square meters. Building production requires a lot of land. In the construction and operation of the process, the direct energy consumption accounts for nearly $30 \%$ of the energy consumption of the whole society. Combined energy consumption of building materials $16.7 \%$, accounting for $46.7 \%$ of the total energy consumption of the whole society. Water is $47 \%$ of urban water consumption, the use of steel products accounted for $30 \%$ of the country's steel consumption, cement accounted for $25 \%$ overall pollution in the environment, and construction-related air pollution, light pollution, and electromagnetic pollution accounted for $34 \%$; and construction waste garbage accounted for $40 \%$ in total [3]. Moreover, the building has increasingly become the city's carbon emissions "big" resource. It is estimated that $60 \%$ of urban carbon emissions are from energy consumption used to maintain the building functions, while car traffic accounts for only about $30 \%$ [4].

With the continuous improvement of the rapid development of China's economy and the people's living standards, building energy in the total energy consumption with the proportion of society will inevitably increase. It is foreseeable that in the next 20 years, the building will become a major growth point of China's energy consumption. When people put forward higher requirements for building management on the urban development, human beings are adjusting their behavior and taking efforts to create new forms of economic and social development. Low carbon and eco-building based urban development model is the choice for the future development.

\section{ISSUES RAISED}

The grand goals of low-carbon eco-city construction and urban development have been set recently, for the urban development is bound to have a profound impact. However, the 
current research on the ecology of the city and a lot of lowcarbon buildings, shows that any correlations between the two is rarely found. What is the impact of development of low-carbon eco-city construction? Whether the synergies between the two objectives could be achieved? Are the two goals not completely separate? Based on these issues, this paper discusses both the association and building of lowcarbon buildings with respect to the urban ecological mutualism management system, thus find the harmonious development of a new path for China's low-carbon eco-city construction.

City's construction is inseparable from the development of construction. Low carbon buildings is the means, the ecocity is the goal. To promote the development of eco-cities, it is bound to change the building's construction and management development mode. In this context, the development of an interactive model ecological city construction and management of research and construction of low-carbon: can reveal the correlation of low-carbon buildings with the ecocity and associated path from a deeper theoretical level, is able to provide support scientific theory for the development strategies for low-carbon eco-city and architecture construction; promote the coordinated development of eco-city construction, and provides a theoretical basis for the eventual development of eco-cities.

\section{EVALUATION METHOD BASED ON ARTIFICIAL NEURAL NETWORK AND ITS ADVANTAGES}

Artificial neural network is composed of a large number of simple information units called neurons in a complex network of connections, and is widely used to simulate the human brain structure and behavior of the network. Its working principle is based on the sample data provided, by a network of learning and training, to identify the intrinsic link between input and output, and thus strike problem solution [5].

Evaluation method based on artificial neural network is defined by the neural network learning and training, establishes the method of comprehensive evaluation model, which is closer to human thinking patterns and combines qualitative and quantitative analyses [4]. Building management evaluation solves problems, compared with the use of traditional evaluation methods, such as AHP, fuzzy theory analysis and other evaluation methods based on artificial neural networks, and thus has significant advantages.

First, evaluating the building management is a very complex problem, a variety of factors influence each other, and there is a complex nonlinear relationship. Artificial neural network model of a typical sample of neural network learning, has a self-learning, self-organizing, adaptive ability and strong advantages of fault tolerance. Trained neural network experts assess by thinking the right way to create a network connection fully reflecting the nonlinear relationship between indicators, that can accurately simulate experts assessed work, reducing the workload of the expert assessment, shortening the evaluation cycle, to avoid the impact of human factors and fuzzy randomness in the evaluation process $[6,7]$.
Second, the current building management theory and its evaluation is not yet mature. Practice is also still in the development stage. There are some differences between different ideas and expert evaluation criteria. How to evaluate the raw data obtained from various experts in the scientific treatment, excluding the impact of which individual data elements, expert evaluation to learn the essence of thought, is a major difficulty of carrying out construction management evaluation. The artificial neural network model has a strong fault-tolerance capability to deal with those noisy or incomplete data, with the generalization capabilities, provides a powerful tool to solve this problem. In addition, the artificial neural network model has a strong self-learning ability. By learning new sample, the knowledge of the network can give more scientific and accurate evaluation results. Thus, the evaluation model has a good growth conducive to the rapid development of construction management and evaluation research.

\section{ECO-CITY AND CONSTRUCTION MANAGE- MENT ASSOCIATION ANALYSIS}

\subsection{Build Self-Organizing Structure of Ecosystems}

Collaborative is a science which researches the rules and characteristics of the system transiting from disorder to order. The so-called collaborative, coordinated system means many subsystems, cooperation or joint action synchronization, which is the intrinsic performance of the system integrity and the correlation [5]. Eco-city and building management is the ecosystem of two subsystems; the presence of both gives a sense of competition between them, which results in a non-harmonious, non-equilibrium state. The cooperative is uniting the movement tendency of some two subsystems such as non-equilibrium conditions between them, to reach a state of equilibrium, so that the whole ecosystem is the orderly development of the state.

In the construction management, three important parameters dominating the evolution of two subsystems i.e. the lowcarbon city and the eco-city, are the fast variable, order parameters and control parameters. Fast variable system had no effect on the entire process of structural change; the order parameter always affect whole process of system evolution, the decision the structure and function of system evolution; Control variable is a role of the external environment on the system, or an incentive [6].

To more complex ecosystems of the two subsystems of low-carbon cities and construction management, its differential equations group is as follows:

$p=r_{j} p_{j}-f_{j}\left(p_{1}, p_{2}, \ldots, p_{n}\right), \mathrm{j}=1,2, \ldots, \mathrm{n}$

Where: $p$ is the system state; $p_{j}$ indicates the state variables, including program variables and fast variables; $r_{j}$ is the damping coefficient.

To simplify the calculations, "adiabatic elimination method" can be used to reduce the fast variable sequences. When the system is in a critical state, it is possible to quickly form an ordered structure. Other external factors has little effect, that is the affect of the internal system parameters changes quickly when the system is not large. Therefore, the 
order parameter can be considered to represent all parameter changes. This can order parameter equation with a few approximate expression system running, so as to form a selforganizing structure. This approach is called the "adiabatic elimination".

Self-organized structure, low carbon cities and construction management of the two systems interact, for collaborative development. We built a self-organizing structure, according to the specific path of interaction with low-carbon eco-city urban environment as well as external control between the quantitative descriptions of the ecosystem, to find the coordinated development of the two subsystems.

(1) From the point of ecological system

$p=r_{j} f_{0}(t)-f(t)$

$p$ represents the state of the eco-city system; $r_{j} f_{0}(t)$ represents the role of ecosystem behavior of the subsystem state produced; $f(t)$ represents the external force.

In this formula, we have found the low-carbon city and eco-city as an economic mean which pursue self-interest maximization. They will make use of external ecological environment to pursue their ecological benefits. In this sense, the behavior is a kind of ecological resistance. Under normal circumstances, the presence of hysteresis effects the state of the system at a certain time not only with the external force at that time, but also on its external force moment about the past. Therefore, the state of the system to show the outside world is proportional to the change in the relationship with time. If the resistance subsystem is very large, then the external force will become weaker. We assume that the external force $f(t)$ changes with time constant attenuation:

$$
f(t)=\frac{a}{e^{\partial t}}
$$

Of which, $\boldsymbol{a}$ is a constant; $\partial$ is damping coefficient. Then the solution of the equation is:

$$
A(t)=\frac{a}{(r-\partial) \cdot e^{r t}}
$$

This can be seen from the impact of external forces on the system, that this process is very rapid, and occurs instantaneously. When the energy exchange system is even faster, this process is a "adiabatic" process. If over time, the decay rate of the system behavior is faster than the force that is far greater than the external damping system damping, then $r>>$ $\delta$.

Usually the above hypothesis that $r$ is far greater than $\partial$, is called "adiabatic approximation." Based on the above formula, we can approximate the view that the state of the system at a time is only due to the external force moment. That is to say, at this time, the order parameter is the dominant state of the system outside force. Behavior of each subsystem will be subject to the external environment. We can also assume, in this case, the state of low-carbon city and ecological city is the same. Then, the system can be configured to maximize both the ecological benefits by choosing a certain behavior.

\section{(2) From the viewpoint of the subsystem}

Moreover, we analyzed the interaction between two subsystems, urban and low-carbon eco-city, and their respective variables. Assuming $\mathrm{X}$ is the internal force generated by one of the subsystems variable, which represents the force generated of self-interest building subsystem; Y represents another subsystem, the force that acts on self-protection subsystem of the eco-city, produced by $\mathrm{X}$, because they have control action. The equations of motion subsystems can be expressed as follows:

$$
\begin{aligned}
& X=-r_{1} \bullet X-X \bullet X \bullet Y \\
& Y=-r_{2} \bullet Y+y \bullet X \bullet X
\end{aligned}
$$

In the above formula, $r_{1}$ and $r_{2}$ represent the damping coefficients, which are constant. When $\mathrm{X}$ eliminates, subsystem $\mathrm{Y}$ is in a stable state. Since $\mathrm{Y}$ shows the presence of damping, under the damping effect $X$ gradually restores to the state of $Y=0$. This also explains that the parameter $r_{1}$ is far greater than 0 . Now suppose that $r_{1}$ is much smaller than $r_{2}$, and let $\mathrm{Y}=0$, then solute the equation $0=-r_{2} \bullet Y+y \bullet X \bullet X$, you can get $[8,9]$ :

$Y(\mathrm{t})=\frac{y \cdot A^{2}}{r_{2}}$

Correspondingly, the variable $\mathrm{Y}$ is also counterproductive in the order parameter $X$, which by coupling relationship with the order parameter $Y$, influences and restricts the formation of order parameter and its role. Substitute the formula (7) into (8):

$X=-r_{1} \bullet X-X \bullet X \bullet Y$

The result obtained is [10] :

$X=-r_{1} \cdot X-\frac{X \cdot y \bullet A^{3}}{r_{2}}$

In this formula, the variable $\mathrm{Y}$ is completely replaced by the order parameter $\mathrm{X}$. We got one evolution equation only containing orderly parameters. Since the whole system is controlled by the order parameter, then the evolution equation will represent the evolution equation of the entire system. On the other hand, with the changes of external conditions, the order parameter $\mathrm{X}$ occurs in similar systems evolution.

Considering the state of the system for different values of $r_{1}$, when $r_{1}$ is much larger than 0 , this time evolution equation has only one stable solution, which is $\mathrm{X}=0$, that is, the system will be in a steady state when $\mathrm{X}=0$.

\section{BUILDING MANAGEMENT EVALUATION MOD- EL BASED ON BP ARTIFICIAL NEURAL NETWORK}

\subsection{The Basic Principle of BP Artificial Neural Network Model}

Here, the use of the BP neural network model with multiinput and single-output as a building management evaluation, gives the following topology as shown in Fig. (1) and Table 1. 


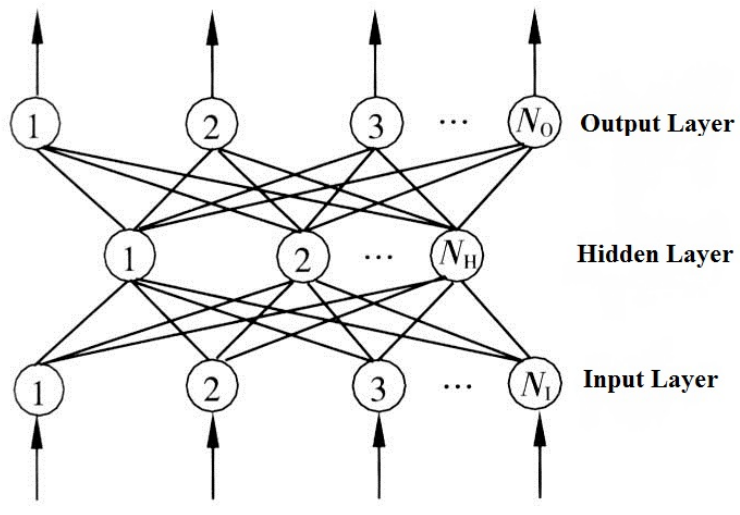

Fig. (1). The three layers of BP neural network topology.

Non-linear relationship between the output and input of each node is described as Sigmoid function, that is:

$f(x)=\frac{1}{1+e^{-x}}$

BP neural network learning and training is a background propagation and correction process $[11,12]$. The total error is defined as samples of actual output and the desired output function is:

$E_{\text {total }}=\frac{1}{2} \sum_{i=1}^{n}\left(b_{i}-b_{i}^{\prime}\right)^{2}$

Table 1. Architecture evaluation index system.

\begin{tabular}{|c|c|c|}
\hline Target & One Level Index & Two Level Index \\
\hline \multirow[t]{12}{*}{$\begin{array}{l}\text { Building manage- } \\
\text { ment indicators }\end{array}$} & \multirow[t]{5}{*}{$\begin{array}{l}\text { Management Norma- } \\
\text { tive }\end{array}$} & $\begin{array}{c}\text { Management Organi- } \\
\text { zation I11 }\end{array}$ \\
\hline & & Investment I12 \\
\hline & & Plan I13 \\
\hline & & Training I14 \\
\hline & & Research I15 \\
\hline & \multirow[t]{7}{*}{$\begin{array}{l}\text { Effectiveness of im- } \\
\text { plementation }\end{array}$} & $\begin{array}{l}\text { Equipment mainte- } \\
\text { nance I } 21\end{array}$ \\
\hline & & $\begin{array}{l}\text { Air pollution control } \\
\text { I } 22\end{array}$ \\
\hline & & Noise Pollution I23 \\
\hline & & $\begin{array}{l}\text { Pollution Prevention } \\
\text { I } 24\end{array}$ \\
\hline & & $\begin{array}{l}\text { Waste Management } \\
\text { I25 }\end{array}$ \\
\hline & & Ecological impact I26 \\
\hline & & $\begin{array}{l}\text { Reduce energy con- } \\
\text { sumption I } 27\end{array}$ \\
\hline
\end{tabular}

\subsection{Obtained Data}

As there are much qualitative factors in the evaluation, so the expert judgment method was used. Highest score is 10 points; the lowest score is 1 point. Then, the expert scoring method for building management was used to make a comprehensive evaluation to obtain their evaluation scores. Using the above method, the organization of 18 experts in $\mathrm{Wu}-$ han artificial construction management assessed the credibility of the authority to obtain higher evaluation results (Table 2).

\subsection{Implementation of Algorithm Model and the Result}

The steps of construction management evaluation model algorithm based on BP artificial neural network are as follows:

(1) Determine the structural parameters of BP network, namely number of nodes in each layer of neurons.

(2) Use MATLAB to establish an artificial neural network, and select the training function;

(3) Input data, start learning and training network. By constantly performing iterative process to meet the learning accuracy.

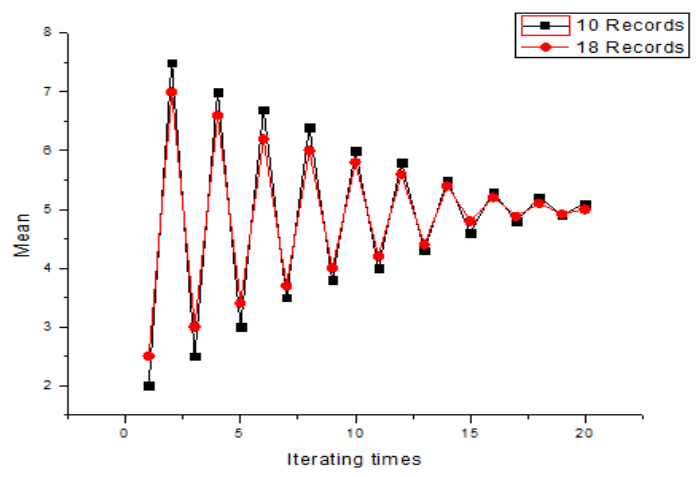

Fig. (2). The expectations of 10 vs. 18 records.

As can be seen from Figs. (2 and 3), with the increase of the number of iterations, the expectation and variance are gradually converged (the iteration times is 20). And the final expectation converges to 5 , the variance converges to 4 . On the other hand, the performance of inputting 18 records is better than the performance of inputting 10 records, which converges faster.

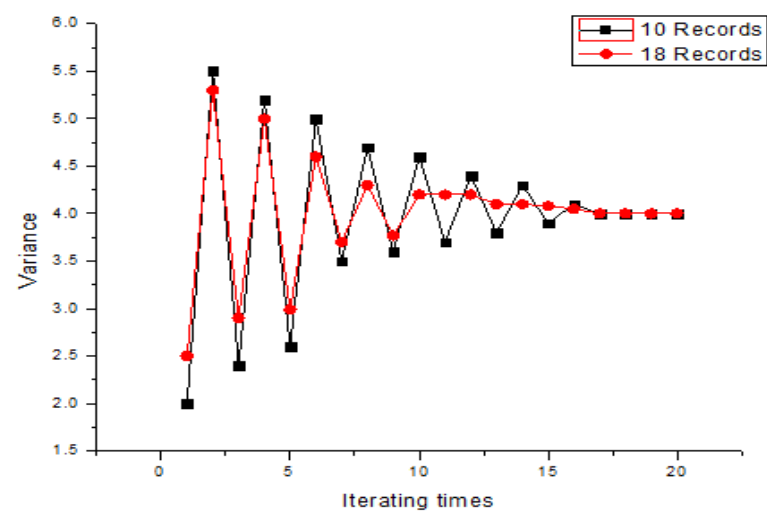

Fig. (3). The variance of 10 vs. 18 records. 
Table 2. The indicator assessment data result.

\begin{tabular}{|c|c|c|c|c|c|c|c|c|c|c|c|c|c|}
\hline No. & I11 & I12 & I13 & I14 & I15 & I21 & I22 & I23 & I24 & I25 & I26 & I27 & Score \\
\hline 1 & 5 & 6 & 3 & 8 & 6 & 2 & 7 & 8 & 1 & 5 & 1 & 7 & 0.78 \\
\hline 2 & 1 & 4 & 3 & 1 & 5 & 5 & 1 & 7 & 4 & 4 & 5 & 4 & 0.69 \\
\hline 3 & 5 & 2 & 3 & 7 & 8 & 4 & 3 & 4 & 8 & 2 & 3 & 4 & 0.48 \\
\hline 4 & 2 & 2 & 4 & 4 & 2 & 9 & 4 & 9 & 4 & 7 & 4 & 1 & 0.88 \\
\hline 5 & 6 & 1 & 4 & 6 & 5 & 2 & 6 & 4 & 9 & 3 & 1 & 7 & 0.51 \\
\hline 6 & 4 & 5 & 1 & 5 & 1 & 7 & 8 & 5 & 5 & 2 & 7 & 2 & 0.75 \\
\hline 7 & 4 & 8 & 7 & 8 & 1 & 2 & 4 & 5 & 9 & 5 & 3 & 1 & 0.22 \\
\hline 8 & 2 & 2 & 8 & 4 & 3 & 1 & 7 & 4 & 6 & 1 & 9 & 4 & 0.80 \\
\hline 9 & 7 & 1 & 7 & 9 & 1 & 3 & 8 & 1 & 4 & 2 & 5 & 1 & 0.55 \\
\hline 10 & 5 & 7 & 8 & 4 & 9 & 1 & 1 & 1 & 5 & 5 & 5 & 1 & 0.64 \\
\hline 11 & 2 & 4 & 3 & 4 & 4 & 2 & 2 & 9 & 1 & 8 & 2 & 2 & 0.38 \\
\hline 12 & 4 & 5 & 7 & 9 & 4 & 2 & 2 & 4 & 7 & 8 & 5 & 5 & 0.53 \\
\hline 13 & 3 & 1 & 2 & 5 & 7 & 5 & 4 & 9 & 6 & 1 & 9 & 1 & 0.66 \\
\hline 14 & 6 & 7 & 8 & 9 & 4 & 8 & 9 & 4 & 5 & 7 & 8 & 5 & 0.81 \\
\hline 15 & 7 & 1 & 7 & 2 & 4 & 2 & 7 & 4 & 4 & 3 & 4 & 3 & 0.28 \\
\hline 16 & 1 & 5 & 3 & 3 & 1 & 8 & 5 & 8 & 6 & 6 & 8 & 9 & 0.39 \\
\hline 17 & 5 & 5 & 4 & 4 & 7 & 4 & 4 & 8 & 6 & 4 & 5 & 4 & 0.44 \\
\hline 18 & 1 & 6 & 6 & 9 & 2 & 2 & 2 & 8 & 5 & 4 & 6 & 7 & 0.55 \\
\hline
\end{tabular}

\section{CONCLUSION}

On the basis of in-depth study based on the large number of documents, current theoretical research of overseas construction management evaluation methods is summarized. Many advanced building management theories and current models are described, as well as learnt government regulations. The study also discussed the basic building management assessment methods employed currently. On the basis of research results based on the major factors influencing construction management in the relevant literatures, a building evaluation system is built for the evaluation of a single object management architecture. The system includes: selecting the artificial neural networks comprehensive evaluation method, obtaining the sample data by questionnaire method, establishing a management evaluation model based on BP artificial neural network architecture, and applying and testing the model to evaluate the actual construction management.

\section{CONFLICT OF INTEREST}

The author confirms that this article content has no conflict of interest.

\section{ACKNOWLEDGEMENTS}

This work is supported by the Soft Science Research Plan Project of Henan Province, China (No.142400411029), and the Soft Science fund of the Science and Technology Department of Henan, China.

\section{REFERENCES}

[1] G.T. Jan, and R.J. Cole, "The role of local governments in fostering green buildings: an ease study", Building Research and information, vol. 29, no. 5, pp. 394-40, 2009.

[2] O. George, G. Gu, and B. Clive, "Implementing environmental management systems in construction: lessons from quality system", Building and Environment, vol. 37, pp. 1397-1407, 2002.

[3] U.S. Green Building Council (USGBC), LEED Reference Guide for Green Building Operations and Maintenance For the Operations and Maintenance of Commercial and Institutional Buildings. Washington D.C., 2009.

[4] L. Ochoa, R. Ries, H.S. Matthews, and C. Hendrickson, "Life Cycle Assessment of Residential Buildings," ASCE, vol. 183, pp. 36-39, 2005.

[5] J.C. Raymond, "Building environmental assessment methods: assessing construction Practices", Construction Management and Economics, vol. 18, no. 8, pp. 949-957, 2000.

[6] U.S. Green Building council. What is LEED? http://www. usgbe.org/, vol. 5, 2009. 
[7] G. Kats, and E. Capital, L. Alevantis, A. Berman, E. Mills, and J. Perlman "The Costs and Financial Benefits of Green Buildings", A Report to California's Sustainable Building Task Force vol. 10, 2003.

[8] A. Schlueter, and F. Thesseling, "Building information model based energy performance assessment in early design stages," $A u$ tomation in Construction, vol. 18, pp. 153-163, 2009.

[9] T.F. Carlos, "Material waste in building industry: main causes and prevention", Journal of Construction Engineering Management, vol. 27, no. 5, pp. 316 331, 2002.
[10] D.J. Craven, H.M. Okraglik, and I.M. Eilenberg, "Construction waste and a new design methodology", Sustainable Construction, vol. 23 , no. 8 , pp. $89-98,2002$

[11] S. Burnley, "The impact of the European landfill directive on waste Management in the United Kingdom", Resources, Conservation and Reeyeling, vol. 32, no. 3-4, pp. 349-358, 2001.

[12] S. Lee, Q. Xu, M. Booth, T. G. Townsend, P. Chadik, and G. Bitton, "Reduced sulfur compounds in gas from construction and demolition debris landfills", Waste Management, vol. 26, no. 5, pp. 526-533, 2006.

Received: September 16, 2014

Revised: December 23, 2014

Accepted: December 31, 2014

(C) Zhenlin Yan; Licensee Bentham Open.

This is an open access articles licensed under the terms of the Creative Commons Attribution-Non-Commercial 4.0 International Public License (CC BY-NC 4.0) (https://creativecommons.org/licenses/by-nc/4.0/legalcode), which permits unrestricted, non-commercial use, distribution and reproduction in any medium, provided that the work is properly cited. 